\title{
CRIAÇÃO E COMPARTILHAMENTO DE CONHECIMENTO: PERFIS PROFISSIONAIS PARA O FUTURO DA INDÚSTRIA PARANAENSE
}

\author{
CREACION Y COMPARTIMIENTO DE \\ CONOCIMIENTO: PERFILES PROFESIONALES \\ PARA EL FUTURO DE LA INDUSTRIA \\ PARANAENSE
}

Karoline Aparecida Scroch Sato - karoline.scroch@gmail.com Mestre em Ciência, Gestão e Tecnologia da Informação pela Universidade Federal do Paraná (UFPR).

Helena de Fátima Nunes Silva - helenanuness@gmail.com Doutora em Engenharia de Produção pela Universidade Federal de

Santa Catarina (UFSC). Professora do Programa de PósGraduação em Ciência, Gestão e Tecnologia da Informação, da Universidade Federal do Paraná (UFPR).

Isabela Drago - isabeladrago@gmail.com Mestre em Ciência, Gestão e Tecnologia da Informação pela Universidade Federal do Paraná (UFPR). Gestora da Informação no Observatório Regional Base de Indicadores de Sustentabilidade

(ORBIS).

Sônia Maria Breda - smkbreda@gmail.com Doutor em Educação pela Universidade Federal do Paraná (UFPR). Professora da UFPR.

\section{RESUMO}

Introdução: Estudo sobre criação e compartilhamento de conhecimento no projeto Perfis Profissionais para o Futuro da Indústria Parananense, dos Observatórios de Prospecção do Sistema Federação das Indústrias do Estado do Paraná (FIEP).

Objetivo: analisa o processo a partir do caso paranaense, partindo dos pressupostos: as organizações atuantes em atividades de prospecção são intensas na criação e compartilhamento do conhecimento; tornar coletivo o 
Karoline Aparecida Scroch Sato; Helena de Fátima Nunes Silva; Isabela Drago; Sônia Maria Breda

Criação e compartilhamento de conhecimento: perfis profissionais para o futuro da indústria paranaense

conhecimento individual constitui um dos principais desafios das organizações inovadoras.

Metodologia: pesquisa exploratória e descritiva, vale-se de pesquisa bibliográfica e documental, observação fundamentada na participação nos painéis de nove especialistas ligados ao Projeto (amostra por tipicidade voltada aos setores metal mecânico, plástico, TIC's e meio ambiente) e realização de entrevistas com os relatores dos painéis. Coteja o material empírico levantado com o referencial pertinente de modo a evidenciar aspectos dessa prática de gestão.

Resultados: com base nos resultados obtidos das análises da documentação da organização, das observações durante os painéis e das entrevistas, percebeu-se que o projeto Perfis Profissionais para o futuro da Indústria Paranaense contempla as cinco fases do processo de criação do conhecimento e também os capacitadores do conhecimento.

Conclusões: Os resultados das entrevistas confirmam os resultados obtidos durante as observações, o que permite perceber que houve consenso no discurso da equipe gestora e dos painelistas em relação ao que se espera como perfil profissional para o futuro da indústria paranaense.

Palavras-chave: Criação do conhecimento. Compartilhamento do conhecimento. Gestão do conhecimento.

\section{INTRODUÇÃO}

Com o uso intensivo da informação e do conhecimento para fins estratégicos, as organizações perceberam que se forem capazes de integrar os processos de criação de significados e de conhecimentos na tomada de decisões estarão à frente das demais (TARAPANOFF, 2006).

No ambiente das organizações e dos negócios, o interesse pelo conhecimento acentua-se com a constatação, de que o valor de mercado, de algumas empresas, chega a ser inúmeras vezes maior do que o valor do patrimônio financeiro e físico que possuem; as ações valem tanto, porque incorporam valores intangíveis, como a marca e a imagem que possuem, a capacidade de inovação, o talento e a competência de seus colaboradores. Esse valor intangível só é possível pela incorporação de novas experiências, de reflexão, da aprendizagem contínua e compartilhada (TONET; DA PAZ, 2006, p. 76).

O desafio das organizações desta nova sociedade é, portanto, 
Karoline Aparecida Scroch Sato; Helena de Fátima Nunes Silva; Isabela Drago; Sônia Maria Breda

Criação e compartilhamento de conhecimento: perfis profissionais para o futuro da indústria paranaense

gerenciar o seu ambiente para que seja possível criar conhecimento. "Empresas criadoras de conhecimento, seriam, pois, aquelas que criam, sistematicamente, novos conhecimentos, disseminam pela organização inteira e, rapidamente, os incorporam as novas tecnologias e produtos." (TERRA, 2001, p. 78). A criação do conhecimento acontece por meio de processos de conversão do conhecimento tácito, que está na mente dos colaboradores, para o conhecimento explícito, formalizado. A inovação pode ser definida como o resultado da criação de conhecimento em equipes de desenvolvimento de produtos, como um resultado de interações e aprendizagem coletiva $(\mathrm{KOCH}, 2011)$. É preciso, portanto, que exista o compartilhamento dos conhecimentos para que gere aprendizado organizacional e a inovação.

A teoria da criação de conhecimento organizacional é um campo de estudos recente dentro da grande área das Ciências Sociais Administração. No decorrer do Século XX, a construção conceitual das principais abordagens teóricas desta ciência estabeleceu um campo de estudos sobre as organizações e todos seus processos envolvidos (THENMOZHI, 2010).

Os estudos de Nonaka, no final do século $\mathrm{XX}$, surgem da necessidade das organizações de deslocarem-se dos fatores de produção tradicionais, para o conhecimento. Temas como gestão, estratégia e gestão do conhecimento, indispensáveis para criação e inovação, passam a ser discutidos tanto do ponto de vista organizacional como acadêmico (LEONARDI; BASTOS, 2014).

Do ponto de vista organizacional, faz-se necessário uma postura pró-ativa de gerenciamento do recurso conhecimento. Na busca de respostas, algumas organizações utilizam técnicas e ou metodologias para auxiliar nas decisões das ações presentes com objetivos futuros mais precisos. Neste sentido, os estudos prospectivos auxiliam na diminuição das incertezas frente ao futuro.

Os estudos prospectivos tiveram início no Japão em 1970 e se 
Karoline Aparecida Scroch Sato; Helena de Fátima Nunes Silva; Isabela Drago; Sônia Maria Breda

Criação e compartilhamento de conhecimento: perfis profissionais para o futuro da indústria paranaense

expandiram fortemente para outros países a partir da segunda metade da década de 90. Nos países do leste europeu, latino-americanos e africanos esta expansão de dá, em grande parte, pelos esforços da UNIDO - United Nations Industrial Development Organization.

Segundo levantamento realizado por Coelho (2003) algumas experiências internacionais que se destacam relacionadas à prospectiva são: o Millenium Project das Nações Unidas; o Futures Project do IPTS - The Institute for Prospective Technological Studies na União Européia; na Espanha os projetos de Prospectiva Tecnológica do OPTI Observatório de Prospectiva Tecnológica Industrial; o Foresight Programme do Reino Unido; o Technologies Clés coordenado pelo OTS - Observatoire des Technologies Strategiques na França; o Delphi/Futur na Alemanha; no Japão os estudos realizados pelo NISTEP - National Institute of Science and Technology Policy; O AEPI - Army Environmental Policy Institute, Logistic nos Estados Unidos; e o Royal Dutch Shell na Holanda.

No Brasil, as atividades de prospecção em nível nacional tiveram início em 1996 com o Projeto Brasil 2020 elaborado pela SAE Secretaria de Assuntos Estratégicos. Algumas outras experiências que se destacam são: ProspeCTar, coordenado pelo MCT - Ministério da Ciência e Tecnologia; o Programa Brasileiro de Prospectiva Tecnológica Industrial da Secretaria de Tecnologia Industrial da MDIC - Ministério do Desenvolvimento, Indústria e Comércio Exterior; o Projeto Tendências, coordenado pela ANP - Agência Nacional do Petróleo, sediado pelo INT - Instituto Nacional de Tecnologia; os estudos temáticos e de futuro do CGEE - Centro de Gestão e Estudos Estratégicos; e o modelo SENAI de Prospecção, uma iniciativa do SENAI Nacional - Serviço Nacional de Aprendizagem Industrial.

Considerando as iniciativas no Estado do Paraná, destacam-se os Observatórios de Prospecção do Sistema FIEP - Federação das Indústrias do Estado do Paraná. Trata-se de uma rede composta por 
Karoline Aparecida Scroch Sato; Helena de Fátima Nunes Silva; Isabela Drago; Sônia Maria Breda

Criação e compartilhamento de conhecimento: perfis profissionais para o futuro da indústria paranaense

três unidades, cada qual relacionada à área de atuação de uma das instituições que compõem a casa (SESI/SENAI/IEL), para atender as vertentes: sociais, tecnológicas e de desenvolvimento industrial de longo prazo. São eles: Observatório de Prospecção e Difusão de Iniciativas Sociais - SESI, Observatório de Prospecção e Difusão de Tecnologia SENAI e Observatório de Desenvolvimento Industrial - IEL.

Acompanhando as tendências globais e com as incertezas frente ao futuro, o Observatório de Prospecção e Difusão de Tecnologia do Serviço Nacional de Aprendizagem Industrial - SENAI preocupou-se com a questão do futuro da indústria paranaense. Iniciou um processo reflexivo com o objetivo de fazer uma análise da situação atual e futura e identificar quais seriam os setores portadores de futuro que poderiam situar o Paraná em posição competitiva, antecipando ações. Para tal iniciou em 2006 um projeto intitulado Setores Portadores do Futuro para o Estado do Paraná com o objetivo de analisar a posição dos setores industriais do Estado do Paraná em relação às tendências apontadas em um horizonte de dez anos.

Com o resultado deste projeto, foi possível elaborar as rotas tecnológicas dos setores identificados, projeto intitulado - Rotas Estratégicas para o Futuro da Indústria Paranaense, que teve como objetivo apontar caminhos de construção do futuro para cada um dos setores e áreas mais promissores para a indústria do Paraná no horizonte de 2015 (FIEP, 2010). Os resultados do projeto das rotas estratégicas evidenciaram a necessidade de formação profissional alinhada com as visões e as tecnologias-chave para o desenvolvimento do Estado. Desta necessidade, surgiu o projeto Perfis Profissionais para o Futuro da Indústria projeto este conduzido pelo Observatório de Prospecção e Difusão de Iniciativas Sociais do SESI/PR e o Observatório de Prospecção e Difusão de Tecnologia do SENAI/PR, que tem como objetivo identificar os perfis profissionais que serão demandados no futuro pelas empresas e pela sociedade (FIEP, 2010). 
Karoline Aparecida Scroch Sato; Helena de Fátima Nunes Silva; Isabela Drago; Sônia Maria Breda

Criação e compartilhamento de conhecimento: perfis profissionais para o futuro da indústria paranaense

Neste sentido, considerando que as organizações que atuam em estudos prospectivos, são intensas na criação e compartilhamento do conhecimento e que um dos principais desafios das organizações está em tornar coletivo o conhecimento individual para aplicação nos processos inovativos das indústrias o presente artigo se propõe a analisar o processo de criação e compartilhamento do conhecimento a partir de um estudo dos Perfis Profissionais para o Futuro da Indústria Paranaense.

\section{REFERENCIAL TEÓRICO}

Nas últimas décadas as organizações se conscientizaram da importância da revisão dos modelos de gestão, em especial as organizações brasileiras que sofreram um atraso em relação à situação mundial. Iniciou-se, portanto, uma busca de novos modelos de gestão que atendessem as tendências mundiais em um mercado cada vez mais globalizado e competitivo e que garantisse a sobrevivência das mesmas (SANTOS et al., 2001, p. 11).

As organizações passam, assim, de um mundo essencialmente mecanicista e racional, para serem vistas na sociedade da informação e do conhecimento como seres vivos e se depararem com a necessidade de se reinventar e se adaptar as novas características dessa sociedade (ANGELONI, 2006, p. 147). Portanto, as profundas mudanças vivenciadas até a sociedade do conhecimento afetaram os ambientes organizacionais resultando em mudanças significativas nos modelos de gestão. Tais mudanças se tornam inevitáveis frente a um momento de questionamentos e transições.

O grande desafio desta nova sociedade, portanto, é trabalhar com o conhecimento humano e poder transformá-lo em produtos e serviços úteis. Isto implica em exigências para que as organizações incrementem a capacidade intelectual e saibam orienta-la para a 
Karoline Aparecida Scroch Sato; Helena de Fátima Nunes Silva; Isabela Drago; Sônia Maria Breda

Criação e compartilhamento de conhecimento: perfis profissionais para o futuro da indústria paranaense

produção de negócios (OLIVEIRA; ALVES FILHO, 2008, p. 52). Este desafio passa a ser uma habilidade fundamental às organizações (CHOO, 2006, p. 28).

O início do desafio está na tentativa de quantificar e de medir o recurso conhecimento, pois ao contrário de recursos financeiros ou naturais, o valor econômico do recurso conhecimento é de difícil compreensão por ser intangível. Porém, o recurso é altamente reutilizável, na medida em que quanto mais se utiliza e se difunde, mais aumenta o seu valor (TERRA, 2001, p. 20).

Organizações que saibam lapidar tal recurso são ditas "do conhecimento", ou seja, são aquelas que possuem "informações e conhecimentos que lhes conferem uma especial vantagem, permitindoIhe agir com inteligência, criatividade e, ocasionalmente, esperteza." (CHOO, 2006, p. 31). A organização do conhecimento também é aquela que aprende, e isto é possível porque todos nós, humanos, somos aprendizes e porque aprender faz parte da natureza humana (SENGE, 2003, p. 38). "O aprendizado é uma das cláusulas do "novo contrato de trabalho" que todas as pessoas assinam com ansiedade." (STEWART, 2002, p. 59).

Assim, com a evolução das sociedades e os desafios impostos da constante revisão dos modelos de gestão, constata-se que as organizações precisam enfrentar estas mudanças e necessitam repensar estruturas voltadas para a valorização do recurso conhecimento, pois a criação e o compartilhamento dos ativos intangíveis passam a ser decisivo para a inovação e competitividade das organizações.

As organizações para vencerem e se manterem competitivas necessitam pensar maneiras e práticas para criar conhecimento organizacional e gerar aprendizagem. "Os novos conhecimentos sempre se originam nas pessoas" (NONAKA, 2000, p. 31).

A criação do conhecimento para as organizações, portanto, 
Karoline Aparecida Scroch Sato; Helena de Fátima Nunes Silva; Isabela Drago; Sônia Maria Breda

Criação e compartilhamento de conhecimento: perfis profissionais para o futuro da indústria paranaense

envolve a capacidade de "adquirir, criar, acumular e explorar o conhecimento". Esta "criação acontece quando o conhecimento dos indivíduos passa a ser cristalizado como parte da organização." (NONAKA; TAKEUCHI, 1997, p. 83). Porém, a criação não é uma "simples compilação de fatos, mas um processo humano singular e irredutível, que não se produz com facilidade." (VON KROGH; ICHIJO; NONAKA, 2001, p. 15).

Para que a construção de conhecimento exista é necessário um relacionamento sinérgico entre o conhecimento tácito e o explícito e a elaboração de processos sociais que possibilitam a criação de novos conhecimentos por meio da conversão do conhecimento tácito em conhecimento explícito (NONAKA; TAKEUCHI, 1997, p. 82-83). "Empresas criadoras de conhecimento, seriam, pois, aquelas que criam, sistematicamente, novos conhecimentos, disseminam-nos pela organização inteira e, rapidamente, os incorporam as novas tecnologias e produtos." (TERRA, 2001, p. 78). O processo de conversão é a interação entre o conhecimento tácito e o explícito. A partir de vários processos de conversão o conhecimento é criado (NONAKA; TAKEUCHI, 1997, p. 82). Neste sentido, a aquisição de conhecimento e a capacidade de geração de conhecimento são importantes antecedentes de inovação a capacidade de combinação do conhecimento contribui de forma efetiva para as atividades de inovação. A Combinação do conhecimento amplia a base de conhecimento o que irá resultar em inovações mais rápidas e eficazes. Além de afetar a combinação de conhecimento a capacidade de aquisição de conhecimento contribui para a capacidade de geração de conhecimento possibilitando a inovação (ZHENG et al., 2011). As condições capacitadoras e os modos de conversão do conhecimento resultam em um modelo integrado das 5 fases do processo de criação do conhecimento organizacional: a) compartilhamento do conhecimento tácito; b) criação de conceitos; c) justificação de conceitos; d) construção 
Karoline Aparecida Scroch Sato; Helena de Fátima Nunes Silva; Isabela Drago; Sônia Maria Breda

Criação e compartilhamento de conhecimento: perfis profissionais para o futuro da indústria paranaense

de arquétipo ou protótipo; e) difusão interativa do conhecimento.

Reconhecida a importância da criação do conhecimento organizacional é necessário que este conhecimento seja compartilhado para que se gerem novos produtos, processos e serviços.

As organizações têm conhecimento disseminado e compartilhado entre todos; entretanto, existem também diversos estoques ou conjuntos de conhecimento pertencentes somente a indivíduos, pequenos grupos ou áreas funcionais. As organizações buscam codificar e simplificar esse conhecimento de indivíduos e grupos para torná-lo acessíveis a toda a organização (OLIVEIRA JUNIOR, 2001, p. 135). A valorização do ser pensante na organização cria um novo contexto relacional no qual a aprendizagem acontece pelas trocas de conhecimento, pelas vivências, pela execução de tarefas que exigem participação de grupos, e não mais o trabalho individualizado (CELADON, 2005, p. 26). As experiências vivenciadas pelos colaboradores precisam ser transmitidas, pois o compartilhamento é vital para o sucesso das organizações e deve ser feito com rapidez e eficiência a toda a organização. "As ideias causam maior impacto quando são amplamente compartilhadas, e não quando mantidas em poucas mentes." (GARVIN, 2000, p. 68). Compartilhamento do conhecimento segundo Lin (2007) é considerado a cultura de interação social onde ocorrem as trocas de experiências e habilidades. Para Ipe (2003) o compartilhamento é basicamente o ato de disponibilizar o conhecimento aos outros para que este possa ser utilizado. Para Bartol e Srivastava (2002) é o compartilhamento de informações, ideias, sugestões e experiências organizacionalmente relevantes do indivíduo com outros indivíduos um dos componentes chaves dos sistemas de Gestão do Conhecimento. E a principal vantagem do compartilhamento é que as ideias e habilidades compartilhadas com alguém não são perdidas e sim dobradas (SVEIBY, 1998 , p. 7). Compartilhar significa trocar, difundir, combinar conhecimento criado tanto no individual como no coletivo, em 
Karoline Aparecida Scroch Sato; Helena de Fátima Nunes Silva; Isabela Drago; Sônia Maria Breda

Criação e compartilhamento de conhecimento: perfis profissionais para o futuro da indústria paranaense

decorrência de interações entre pessoas e grupos que alcancem toda a organização, até que o conhecimento seja institucionalizado e incorporado às rotinas, processos, práticas e normas organizacionais (OLIVEIRA; ALVES FILHO, 2008, p. 52).

As interações e trocas ocorrem entre as pessoas de uma determinada comunidade, por meio das trocas de informações, interações online e, também, simultaneamente, pela participação desses indivíduos em outras comunidades nas quais ocorrem discussões e trocas de conhecimentos tácitos e explícitos o que pode resultar a criação de novos conhecimentos (ONO, 2014).

O desafio é como compartilhar conhecimento e como facilitar 0 compartilhamento. De acordo com Davenport e Prusak (1998, p. 107) o compartilhamento acontece quando a organização contrata pessoas perspicazes e deixa que estas pessoas conversem entre si. A questão já conhecida é que o conhecimento tácito é de difícil transferência e de que o compartilhamento é uma tarefa difícil. Por este motivo, as organizações devem facilitar o compartilhamento. É preciso criar processos e orientação e/ou de aprendizado para que os conhecimentos tácitos que são importantes na organização não fiquem concentrados em uma única pessoa (DAVENPORT; PRUSAK, 1998, p. 99). Segundo Nonaka e Takeuchi (1997, p. 69), "o segredo para a aquisição do conhecimento tácito é a experiência. Sem alguma forma de experiência compartilhada, é extremamente difícil para uma pessoa projetar-se no processo de raciocínio do outro indivíduo".

O compartilhamento, uma das fases do processo de criação do conhecimento torna-se extremamente necessário para organizações inovadoras e competitivas, para tanto é necessário que sejam criadas condições propícias para que este compartilhamento efetivamente ocorra entre os colaboradores. O compartilhamento entre as equipes propicia o aprendizado organizacional. O conhecimento gerado necessita ser compartilhado e utilizado em todas as fronteiras 
Karoline Aparecida Scroch Sato; Helena de Fátima Nunes Silva; Isabela Drago; Sônia Maria Breda

Criação e compartilhamento de conhecimento: perfis profissionais para o futuro da indústria paranaense

organizacionais.

No processo de criação e compartilhamento, as pessoas exercem papel fundamental, pois o conhecimento surge, se desenvolve e é disseminado por meio delas. Assim, a geração de novos conhecimentos e inovações viabiliza-se unicamente com 0 engajamento e o comprometimento das pessoas (DRAGO; SILVA; SATO, 2014).

Haaapalainen e Mäkiranta (2013) afirmam que o compartilhamento de conhecimento deve ser considerado, tanto em nível individual e organizacional, mas é primordial que a organização esteja atenta para as seguintes questões: Qual é o propósito de compartilhamento de conhecimento? Como e com que finalidade 0 conhecimento será utilizado pelo destinatário?

A facilitação do compartilhamento de conhecimento pode ser realizada por meio de algumas atividades que tornam 0 ambiente propício a criação do conhecimento.

Von Krogh, Ichijo e Nonaka (2001, p. 17) apontam que "a capacitação do conhecimento deve ser vista de maneira circular; objetivar sempre a ampliação do potencial de criação do conhecimento." Para isto, apresentam cinco capacitadores do conhecimento que são atividades que afetam positivamente a criação do conhecimento e preparam o ambiente para o compartilhamento. São eles:

a) Capacitador 1- Instilar a visão do conhecimento - as organizações têm dificuldade de estabelecer qual conhecimento necessitam no futuro para tomar decisões. Este capacitador possibilita a capacidade de "prever" o desempenho e sucesso futuro da organização.

b) Capacitador 2 - Gerenciar conversas - este capacitador apresenta uma das principais maneiras de compartilhar e criar conhecimento: as conversas, ou seja, os relacionamentos entre os colaboradores. Criar espaços e ocasiões de encontro dentro ou fora da organização para que as pessoas possam interagir informalmente pode ser um meio de fomentar o compartilhamento. Estes eventos também 
Karoline Aparecida Scroch Sato; Helena de Fátima Nunes Silva; Isabela Drago; Sônia Maria Breda

Criação e compartilhamento de conhecimento: perfis profissionais para o futuro da indústria paranaense

podem ser importantes para manter o espírito de equipe e o comprometimento (MUSSI; ANGELONI, 2008, p. 23).

c) Capacitador 3 - Mobilizar ativistas do conhecimento - Para Von Krogh, Ichijo e Nonaka (2001, p. 13) o ativista do conhecimento é um "gerente dotado de ampla visão social e intelectual, além de experiência nos detalhes das operações da empresa". Este capacitador tem como objetivo estabelecer pessoas, grupos ou setores que irão coordenar e facilitar o processo de criação de conhecimento.

d) Capacitador 4 - Criar o contexto adequado - para que 0 conhecimento seja compartilhado na organização é importante que exista um ambiente propício para que exista este compartilhamento. A estrutura organizacional deve ser trabalhada bem como a cultura organizacional para propiciar o compartilhamento. Um aspecto importante que deve existir neste ambiente é a facilidade de comunicação entre os departamentos, unidades o que torna possível a troca de informações, experiências e resultados (CELADON, 2005, p. 27).

Para Von Krogh, Ichijo e Nonaka (2001, p. 217) o contexto capacitante é um dos principais fatores que impulsionam a criação do conhecimento, este contexto é chamado de "ba" que significa o contexto ideal para a criação do conhecimento, espaço propício para o constante compartilhamento. A palavra tem origem japonesa e a tradução aproximada é de local onde acontece um fato. É um contexto compartilhado para novos relacionamentos, podendo servir como fundação para a criação do conhecimento. Fornece sustentação para o conhecimento individual e/ou coletivo (OUTI; STRAUHS, 2004). O ba é importante para acumular e compartilhar o conhecimento tácito (STEWART, 2002, p. 65).

e) Capacitador 5 - Globalizar o conhecimento local - este último capacitador tem como objetivo transmitir o conhecimento a toda organização. Este depende diretamente dos quatro anteriores, pois a 
Karoline Aparecida Scroch Sato; Helena de Fátima Nunes Silva; Isabela Drago; Sônia Maria Breda

Criação e compartilhamento de conhecimento: perfis profissionais para o futuro da indústria paranaense

visão do conhecimento concentra a atenção nos conhecimentos fundamentais; as conversas são o meio para compartilhar; os ativistas auxiliam na coordenação das atividades e difundem o conhecimento; e o contexto adequado define as formas de compartilhamento de acordo com as estratégias, cultura e valores da organização (VON KROGH; ICHIJO; NONAKA, 2001, p. 254).

\section{ENCAMINHAMENTO METODOLÓGICO}

Caracterizado como pesquisa exploratória e descritiva, o estudo valeu-se de pesquisa bibliográfica e documental, observação fundamentada na participação em painéis de especialistas externos à FIEP que contribuíram para o estabelecimento dos Perfis Profissionais para o Futuro da Indústria (amostra por tipicidade voltada aos setores Metal Mecânico, Plástico, TIC e Meio Ambiente) e realização de entrevistas com nove relatores dos painéis.

O painel de especialistas é uma metodologia que tem como objetivo construir conhecimento, comparando pontos de vista e opiniões por meio da condução de um grupo de pessoas seleto para realizar uma reflexão estratégica sobre a posição atual e as oportunidades futuras em um horizonte pré-definido e propor estratégias de ação. Em geral a composição de um painel inclui especialistas no tema em discussão, sejam formadores de opinião, sejam capazes de pensar o futuro, sejam lideranças ou representantes de comunidades e já tenham trabalhado em projetos relacionados à temática. As atividades são conduzidas por uma equipe específica (SENAI, 2005, p. 5).

Esta equipe, denominada de gestora, é a responsável pela condução dos painéis. Composta pelo coordenador do projeto e cerca de cinco pesquisadores. A função da equipe gestora, durante os painéis, é de apresentar o estudo com seus objetivos e metodologia, conduzir e orientar os convidados (profissionais, empresários e acadêmicos, 
Karoline Aparecida Scroch Sato; Helena de Fátima Nunes Silva; Isabela Drago; Sônia Maria Breda

Criação e compartilhamento de conhecimento: perfis profissionais para o futuro da indústria paranaense

atuantes no setor de análise), por meio de perguntas e reflexões ao diálogo e consenso sobre uma lista de quais seriam os perfis profissionais.

Para a observação dos painéis, elaborou-se um quadro sinótico baseado no referencial teórico, cruzando as fases do processo de criação de conhecimento propostas por Nonaka e Takeuchi (1997) e os capacitadores do conhecimento propostos por Von Krogh, Ichijo e Nonaka (2001).

Os painéis de especialistas foram previamente agendados com os participantes, os quais receberam, antecipadamente, um documento contendo informações sobre o painel bem como os perfis identificados pela equipe gestora como sendo de futuro, para que estes pudessem fazer uma pré-análise do conteúdo. Antes dos encontros, os especialistas foram convidados a participar de um almoço, momento este para a socialização e "quebra do gelo", com o intuito, segundo Nonaka e Takeuchi (1997) de criar um ambiente propício ao compartilhamento e criação de conhecimento. Cada painel contou com a participação de em média 25 especialistas, totalizando uma população de 100 pessoas. A amostra por tipicidade foi constituída por dois especialistas eleitos como locutores que participaram destes mesmos quatro últimos painéis. Exceção foi dada ao painel de Meio Ambiente onde foram escolhidos três especialistas, sendo dois deles os locutores e um participante a mais que se disponibilizou para participar da entrevista; totalizando uma amostra de 9 especialistas.

Durante a observação feita pelas pesquisadoras foi utilizado o roteiro elaborado para identificar as cinco fases do processo de criação de conhecimento e os capacitadores do conhecimento, além da gravação em vídeo. Cada encontro teve duração média de 6 horas, sendo realizadas filmagem e gravação de áudio na íntegra.

Posteriormente aos painéis, os especialistas foram convidados a participar de uma entrevista para refinamento dos perfis. A seleção dos 
Karoline Aparecida Scroch Sato; Helena de Fátima Nunes Silva; Isabela Drago; Sônia Maria Breda

Criação e compartilhamento de conhecimento: perfis profissionais para o futuro da indústria paranaense

entrevistados foi feita de maneira aleatória, tentando tornar essa amostra diversificada com relação à representação dos membros das universidades e empresas públicas e privadas.

A sistematização dos dados coletados foi feita tendo como base a análise de conteúdo proposta por Bardin (2010). As categorias de análise foram elaboradas a partir de um enfoque qualitativo, não havendo intenção de provar hipóteses.

\section{RESULTADOS}

A análise empírica trouxe algumas considerações resultantes das especificidades dos diferentes setores. No painel de metal-mecânico, pode-se perceber, durante a observação, que os participantes estavam mais engajados nas atividades, havia uma harmonia entre eles. Isto se deve ao fato de este setor já estar articulado. Esses especialistas já estão acostumados a trabalharem juntos, portanto a conversa fluiu facilmente, porém com algumas dificuldades conceituais.

No painel de plástico, notou-se que havia menos especialistas. Este setor ficou com um déficit maior de participantes, tornando as conversas mais polarizadas. Observou-se também que as pessoas não estavam articuladas de maneira geral não tinham experiências anteriores de trabalhos conjuntos.

No painel de TIC pode-se identificar que na discussão inicial para definição dos perfis houve um consenso rápido, porém quando a conversa foi aberta para a plenária maior, houve dificuldades dos participantes em chegar a um consenso. O painel se estendeu além do horário previsto e percebeu-se que o consenso se deu pelo esgotamento da discussão. Houve muita dificuldade de compreensão de conceitos entre os grupos.

No painel de meio ambiente, pode-se notar com maior incidência que nos outros painéis a inibição de alguns especialistas em colocar 
Karoline Aparecida Scroch Sato; Helena de Fátima Nunes Silva; Isabela Drago; Sônia Maria Breda

Criação e compartilhamento de conhecimento: perfis profissionais para o futuro da indústria paranaense

seus pontos de vista, devido ao fato de estarem presentes especialistas de renome da área.

\subsection{Processo de Criação e Compartilhamento do Conhecimento}

A primeira fase do processo de criação do conhecimento - 0 compartilhamento - é uma fase crítica à criação do conhecimento organizacional, por envolver o conhecimento tácito de vários indivíduos com diferentes históricos, perspectivas e motivações (NONAKA; TAKEUCHI, 1997, p. 97). Pelos resultados obtidos, verificou-se que durante os painéis houve o compartilhamento do conhecimento tácito fonte rica e inexplorada de novos conhecimentos (NONAKA; TAKEUCHI, 1997, p. 97).

Durante todos os painéis, pôde-se identificar tanto fatores facilitadores como fatores inibidores ao compartilhamento. $\mathrm{O}$ ambiente adaptado para realização dos painéis foi propício ao compartilhamento, pois os participantes puderam trocar idéias antes do início das atividades, no momento do almoço, durante a reunião ficaram dispostos em mesas redondas facilitando o contato visual e permitindo a inclusão de todos. Os momentos do cafezinho foram propícios ao compartilhamento.

Outro facilitador encontrado durante os painéis foram os momentos de informalidade. Durante os debates, por exemplo, os participantes faziam brincadeiras, de maneira a tornar a conversa mais descontraída, ou, até mesmo a equipe gestora iniciava tal conversa, muitas vezes para "quebrar o gelo" da equipe.

Os fatores inibidores ao compartilhamento do conhecimento observados durante a realização dos paneis foram: a crença de que o conhecimento é poder; a linguagem não consensual; a resistência a novas ideias; a intolerância a erros e necessidade de ajuda pelos demais participantes; a limitação do tempo também foi percebida em todos os painéis; e a diversidade cultural como fator negativo foi 
Karoline Aparecida Scroch Sato; Helena de Fátima Nunes Silva; Isabela Drago; Sônia Maria Breda

Criação e compartilhamento de conhecimento: perfis profissionais para o futuro da indústria paranaense

identificada no painel de TIC's.

As explicações e a mobilização à participação também permitem que a confiança seja criada. As emoções, sentimentos e modelos mentais dos indivíduos têm de ser compartilhados para permitir o desenvolvimento de confiança mútua (NONAKA; TAKEUCHI, 1997, p. 97).

Em relação à equipe gestora, identificou-se que foram planejados ambientes propícios ao compartilhamento. Em especial o momento do almoço, do café, a disposição das mesas redondas. Os fatores questionados como facilitadores foram: o ambiente propício, momentos de informalidade, linguagem, capacidade de absorção, interação, reciprocidade, confiança, diálogo, diversidade de interesses, acesso antecipado ao documento e motivação. Um dos fatores principais para facilitar a troca, apontado por todos da equipe gestora foi a apresentação inicial e a condução do método. Identificou-se, também, pela equipe gestora, que o método foi sendo lapidado ao longo dos painéis. Os painelistas também apontaram, em sua maioria, que a condução do painel foi o principal fator facilitador.

Outro fator facilitador considerado tanto pela equipe gestora quanto pelos especialistas foram os momentos de informalidade, que de maneira geral foram considerados positivos, porém sem perder 0 profissionalismo.

Com relação à linguagem, de maneira geral foi consensual. Conforme comentários da equipe gestora, cada setor tem seu vocabulário específico e podem existir divergências com relação aos conceitos preestabelecidos, porém a equipe procurou adequar a linguagem aos participantes.

No quesito capacidade de absorção, a equipe gestora foi unânime em dizer que é muito relativo falar de absorção. Todos consideraram que houve uma ampliação dos conhecimentos e que a interação entre empresariado e academia proporcionada pelo painel é 
Karoline Aparecida Scroch Sato; Helena de Fátima Nunes Silva; Isabela Drago; Sônia Maria Breda

Criação e compartilhamento de conhecimento: perfis profissionais para o futuro da indústria paranaense

um fator muito positivo. Contudo, não entenderam ter havido um aprendizado efetivo. Os painelistas, em sua maioria, consideraram que, de alguma maneira, houve um acréscimo de conhecimento.

Os painelistas apontaram a diversidade de interesses como um fator positivo. Porém, dois deles entenderam que, no painel específico de meio ambiente, no qual surgiram muitas questões conceituais, a diversidade pode ter dificultado um pouco o diálogo. Quando os modelos mentais são compartilhados forma-se um campo de interação e a equipe auto-organizada expressa esse modelo por meio do diálogo contínuo, sob a forma de reflexão coletiva. Durante os debates foi possível identificar a utilização de deduções, induções, comparações, suposições e analogias para tentar chegar ao consenso. Fatores estes apontados como facilitadores por Nonaka e Takeuchi (1997, p. 98).

Os fatores que mais apareceram como motivadores ao processo, tanto pela equipe gestora quanto pelos painelistas, foram o próprio resultado que o projeto poderá trazer ao setor, a condução e a dinâmica no processo de construção dos perfis e o fato de fazer parte da publicação.

Com relação aos fatores inibidores, questionou-se, tanto a equipe gestora quanto os painelistas: se havia pessoas que não queriam compartilhar, se houve sentimento de perda de tempo, se a diversidade cultural foi um fator negativo, se houve falta de compreensão, se houve resistência a novas ideias, receio de expor dúvidas, se o tempo foi um fator limitador e se houve acomodação e ameaça à autoimagem.

Pode-se observar que todos os entrevistados da equipe gestora consideraram haver "uma certa" resistência em compartilhar. Os painelistas em geral, ao contrário da equipe gestora, apontaram que não houve sentimento de não querer compartilhar, todos estavam abertos à troca.

No que se refere ao sentimento de perda de tempo, nenhum dos entrevistados da equipe gestora teve tal percepção. Com relação aos 
Karoline Aparecida Scroch Sato; Helena de Fátima Nunes Silva; Isabela Drago; Sônia Maria Breda

Criação e compartilhamento de conhecimento: perfis profissionais para o futuro da indústria paranaense

painelistas, apenas um deles apontou que houve sentimento de perda de tempo.

A diversidade cultural foi um fator positivo ao processo, segundo a equipe gestora e os painelistas. O principal aspecto apontado foi com relação ao entendimento do que é realmente um perfil.

Com relação à segunda fase do processo de criação do conhecimento, a criação de conceitos, foi possível identificar, durante os debates, que houve a conversão do conhecimento tácito dos participantes. Os modelos mentais compartilhados pelos participantes foram sendo criados por meio da interação e diálogo estabelecidos pela equipe. Os debates acerca dos perfis foram sendo verbalizados em palavras e cristalizados em conceitos explícitos nos roteiros da equipe gestora. O processo também contou com o auxílio dos membros da equipe gestora que também estimulou a criação dos conceitos. Estes estímulos incentivaram os especialistas à criação de conceitos, a análise do perfil.

A segunda fase do processo, a criação de conceitos, é apontada pela equipe gestora do Projeto Perfis Profissionais como o momento em que os painelistas são convidados a debater sobre os perfis já propostos e criar uma nova abordagem, considerando inclusive novas possibilidades. Três dos entrevistados da equipe gestora disseram que a construção dos conceitos se dá pela experiência dos especialistas, comparando a vivência deles aos perfis já propostos.

Quanto à terceira fase do processo - a justificação de conceitos -, pôde-se perceber que, na sequência dos debates para tomada de decisão sobre os conceitos, os especialistas que propunham alguma alteração ou criação de perfis justificavam sua decisão, enquanto os demais membros da equipe avaliavam a real importância da proposição. Conforme apontado por Nonaka e Takeuchi (1997, p. 99) "novos conceitos criados por indivíduos ou equipes precisam ser justificados em algum momento, no procedimento" 
Karoline Aparecida Scroch Sato; Helena de Fátima Nunes Silva; Isabela Drago; Sônia Maria Breda

Criação e compartilhamento de conhecimento: perfis profissionais para o futuro da indústria paranaense

Identificou-se pelo discurso dos especialistas que o conceito que foi criado anteriormente passou por um julgamento para avaliar a sua real importância no contexto dos perfis profissionais. Observou-se, também, a estreita proximidade da equipe gestora no auxílio à definição de critérios de justificação que estivessem alinhados ao objetivo das atividades, diminuindo mal-entendidos e interpretações errôneas. Observou-se, também, a estreita proximidade da equipe gestora no auxílio à definição de critérios de justificação que estivessem alinhados ao objetivo das atividades, diminuindo mal-entendidos e interpretações errôneas. Nonaka e Takeuchi (1997, p. 99) apontam que tal proximidade é necessária, que a organização, no caso a equipe gestora, deve conduzir a justificação de forma explícita a fim de verificar a intenção e ter a certeza de que os conceitos criados atendem às necessidades.

A construção do arquétipo, na visão dos entrevistados da equipe gestora e dos painelistas se deu ao longo dos painéis, continuará nas entrevistas para validação dos perfis e se materializará no documento a ser publicado, chegando à última fase do processo, a difusão do conhecimento, que se deu em vários momentos durante o painel. Segundo Nonaka e Takeuchi (1997) esta fase é considerada complexa sendo necessária a cooperação dinâmica entre todos. E realmente foi uma fase crítica ao processo, em todos os painéis, pois muitos participantes não concordavam com os conceitos criados pelas outras equipes e houve debate até a construção efetiva do documento síntese dos perfis selecionados.

A última fase do processo de criação do conhecimento - difusão - pôde ser analisada em várias etapas da realização dos painéis. No momento em que os locutores de cada equipe apresentaram suas conclusões, houve a difusão do conhecimento gerado para as demais equipes. E, posterior à entrevista, na última etapa do projeto, a materialização dos resultados gerados durante as etapas anteriores, houve a difusão, em uma publicação para a disseminação do resultado 
Karoline Aparecida Scroch Sato; Helena de Fátima Nunes Silva; Isabela Drago; Sônia Maria Breda

Criação e compartilhamento de conhecimento: perfis profissionais para o futuro da indústria paranaense

final. Para Nonaka e Takeuchi (1997, p. 101) este é um processo atualizado continuamente, não terminando com a conclusão do arquétipo, podendo expandir-se, precipitando um novo ciclo de criação do conhecimento.

\subsection{Fases do Processo de Criação do Conhecimento e Capacitadores do Conhecimento}

Quanto aos capacitadores do conhecimento observou-se que houve a disseminação da visão, primeiro capacitor, de onde se pretendia chegar. A equipe gestora buscou, por meio de uma abordagem estruturada, de um processo pré-definido - o painel de especialistas - orientar as reflexões sobre o que os participantes deveriam debater e o que não deveriam para atingir o objetivo do estudo. É preciso tornar nítida a visão de onde se quer chegar para um melhor aproveitamento do conhecimento (VON KROGH, ICHIJO e NONAKA, 2001).

A equipe gestora também procurou nivelar o conhecimento dos participantes. Houve por parte da equipe gestora o estímulo a busca de novas ideias e iniciativas, quando se percebia que havia uma quebra nas discussões.

O segundo capacitador - gerenciar as conversas - propõe que é por meio das conversas, ou seja, do relacionamento, que as ideias são expostas, refletidas sob diferentes pontos de vista gerando, assim, conhecimento. Conforme afirmam Von Krogh, Ichijo e Nonaka (2001, p. 156) é o intercâmbio de ideias, opiniões e crenças propiciado pelas conversas que torna possível o primeiro e mais importante passo para a criação do conhecimento - o compartilhamento. Este é o momento da socialização.

O terceiro capacitador - mobilizar os ativistas do conhecimento tem como objetivo o estabelecimento de pessoas que irão coordenar e facilitar o processo de criação do conhecimento. Este ativista detém 
Karoline Aparecida Scroch Sato; Helena de Fátima Nunes Silva; Isabela Drago; Sônia Maria Breda

Criação e compartilhamento de conhecimento: perfis profissionais para o futuro da indústria paranaense

informações e conecta as iniciativas. "Os ativistas são fundamentais para a nivelação do conhecimento, pois são as pessoas responsáveis pela energização e integração dos esforços de criação do conhecimento" (VON KROGH, ICHIJO e NONAKA, 2001, p. 182). Neste sentido, considerando os painéis de especialistas, identifica-se que a equipe gestora fez o papel de mobilização, coordenando as iniciativas para a criação do conhecimento.

O quarto capacitador - criar o contexto adequado - considera que é importante a existência de um ambiente propício para que o compartilhamento efetivamente aconteça. Para tanto, deve haver uma estrutura e cultura propícias. A comunicação também facilita a troca de informações, experiências e resultados (CELADON, 2005, p. 27). Verificou-se, durante os painéis que a equipe gestora procurou criar este ambiente propício. Novamente conforme já mencionado, os momentos do almoço e do café facilitam a criação deste ambiente. A equipe também procurou estimular a socialização e a conversa entre os participantes, facilitando, quando necessário a comunicação entre eles, afirmando que não precisava haver receio em compartilhar.

Este papel do facilitador foi fundamental para guiar as conversas e se chegar à visão do conhecimento, e, desta maneira, foi estimulada a criação das micro comunidades de conhecimento.

$\mathrm{O}$ ambiente criado foi para que houvesse a troca. Na medida do possível, os espaços foram criados para que estimulassem 0 compartilhamento.

O último capacitador - globalizar o conhecimento local - o qual tem como objetivo disseminar o conhecimento gerado, dependendo, para isto, dos quatro facilitadores anteriores: as conversas como o meio para compartilhar; os ativistas auxiliando na coordenação das atividades e difundindo o conhecimento; e o contexto adequado definindo as formas de compartilhamento de acordo com as estratégias, cultura e valores (VON KROGH; ICHIJO; NONAKA, 2001, p. 254). Verificou-se 
Karoline Aparecida Scroch Sato; Helena de Fátima Nunes Silva; Isabela Drago; Sônia Maria Breda

Criação e compartilhamento de conhecimento: perfis profissionais para o futuro da indústria paranaense

que o conhecimento foi compartilhado e transmitido. Primeiramente, a equipe disseminou o conhecimento criado pelas pesquisas para identificação dos "proto-perfis" a serem analisados pelos especialistas, posteriormente cada especialista socializou seu conhecimento, alinhando ao conhecimento dos demais membros para posterior apresentação das conclusões ao grupo maior. Entende-se que a globalização do conhecimento, será feita quando da publicação dos resultados obtidos, inclusive com a entrevista realizada com os especialistas para refinamento dos perfis selecionados.

\subsection{Perfis Profissionais para o Futuro}

A Federação das Indústrias do Paraná foi a propulsora da articulação para a elaboração dos Perfis Profissionais para o Futuro. Primeiramente, foi elaborado um documento contento a visão, a partir de pesquisas, do que seria necessário, em termos profissionais, ao Estado do Paraná. Este documento foi encaminhado aos convidados que participaram dos painéis de especialistas (indústria e universidade) nos setores citados anteriormente. No início dos painéis houve uma palestra com um especialista da área para apresentar algumas tendências e características do setor, propiciando, também, um ambiente de linguagem comum para a troca. Na sequência, a coordenadora do projeto explicou o histórico, bem como os objetivos e etapas do projeto.

Em seguida, um dos pesquisadores apresentou as tendências de cada setor, que nada mais era do que um resumo do documento que os especialistas receberam anteriormente, por e-mail. Esta contextualização foi importante, pois conforme comentam Nonaka e Takeuchi (1997, p. 97) para conseguir esse compartilhamento, precisase de um "campo" no qual indivíduos possam interagir uns com os outros por meio de diálogos pessoais. Vários membros trabalham juntos para alcançar uma meta comum. Durante os painéis esse "campo" foi criado. A apresentação para contextualização também foi importante, 
Karoline Aparecida Scroch Sato; Helena de Fátima Nunes Silva; Isabela Drago; Sônia Maria Breda

Criação e compartilhamento de conhecimento: perfis profissionais para o futuro da indústria paranaense

pois propiciou que a linguagem fosse comum entre os participantes. Em todos os momentos das explanações, os participantes foram convidados a compartilhar, dialogar, interagir e se envolver no processo.

Pode-se perceber que depois das explicações e apresentações de tendências e perfis, houve dificuldade para que fossem iniciadas as discussões. Pode-se perceber "uma certa" falta de confiança em compartilhar conhecimentos, pois, mesmo com o momento de sensibilização do almoço e com as apresentações pessoais não se sabia ao certo o que deveria ser feito na prática e, como os demais participantes iriam reagir. Neste momento, o papel do moderador, da equipe gestora foi fundamental, pois explicou como deveria ser o debate e induziu ao início do compartilhamento, iniciando, assim, as atividades.

Pelas observações e entrevistas foi possível perceber que a criação dos perfis se deu de três maneiras distintas: uma somente baseada na realidade, no presente, outra no presente aliada às tendências, que aparece com maior frequência e, uma última pensando em um futuro inovador, este último caso ocorreu com menos frequência.

Pelos resultados da observação e entrevista foi possível identificar como ocorreu o processo de criação e compartilhamento do conhecimento no Projeto Perfis Profissionais para o Futuro da Indústria, realizado pelos Observatórios de Prospecção Estratégica da Federação das Indústrias do Estado do Paraná - FIEP.

\section{CONSIDERAÇÕES FINAIS}

Comparando os resultados obtidos pela análise da observação dos painéis e das entrevistas, é possível identificar que muitos aspectos se repetem. Estes estão relacionados aos facilitadores, a condução do painel pela equipe gestora, os pequenos grupos de discussão que tornam a conversa facilitada, a interação que os painéis promovem entre academia e empresariado, a motivação com o resultado que o projeto 
Karoline Aparecida Scroch Sato; Helena de Fátima Nunes Silva; Isabela Drago; Sônia Maria Breda

Criação e compartilhamento de conhecimento: perfis profissionais para o futuro da indústria paranaense

pode trazer e a possibilidade de participar da publicação dos resultados.

Em alguns painéis foi possível perceber que conhecimento é ainda percebido como poder, a linguagem muitas vezes não consensual entre os especialistas, principalmente com relação aos conceitos, a resistência a novas ideias, a acomodação de alguns participantes que se isolavam devido à sobreposição de alguns sobre os outros e a limitação do tempo devido à extensão dos debates.

Com relação aos capacitadores do conhecimento, verifica-se que tanto a equipe gestora quanto os painelistas apontaram que foi instilada a visão do conhecimento, houve o gerenciamento das conversas, sem definição de regras e com intervenções quando necessário.

A criação e o compartilhamento do conhecimento foram mostrados em dimensão empírica, nesta descrição do processo de criação e compartilhamento do conhecimento, no projeto Perfis Profissionais para o Futuro da Indústria Paranaense, realizado pelos Observatórios de Prospecção Estratégica da Federação das Indústrias do Estado do Paraná. Os resultados levantados contribuem para ilustrar a dimensão teórica de estudos organizacionais voltados ao uso da informação e do conhecimento como propulsores da inovação.

\section{REFERÊNCIAS}

ANGELONI, Maria Terezinha. Em busca do aprendizado: análise de modelos de gestão de organizações da era do conhecimento. In: STAREC, Cláudio; GOMES, Elizabeth Braz Pereira; CHAVES, Jorge Bezerra Lopes (Org.) Gestão estratégica da informação e inteligência competitiva. São Paulo: Saraiva, 2006.

BARDIN, Laurence. Análise de conteúdo. Lisboa: Edições 70, 2010. 
Karoline Aparecida Scroch Sato; Helena de Fátima Nunes Silva; Isabela Drago; Sônia Maria Breda

Criação e compartilhamento de conhecimento: perfis profissionais para o futuro da indústria paranaense

BARTOL, Kathryn M.; SRIVASTAVA, Abhishek. Encouraging knowledge sharing: the role of organizational reward systems. Journal of Leadership \& Organizational Studies, Thousand Oaks, v. 9, n.1, p 6477, 2002.

CELADON, Kleber Luís. O compartilhamento do conhecimento no âmbito intra-empresarial: um estudo de caso. 2005. 96 p. Dissertação (Mestrado em Tecnologia) - Universidade Tecnológica Federal do Paraná, 2005.

$\mathrm{CHOO}$, Chun Wei. A organização do conhecimento: como as organizações usam a informação para criar significado, construir conhecimento e tomar decisões. São Paulo: Senac, 2006.

COELHO, Gilda Massari. Prospecção tecnológica: metodologias e experiências nacionais e internacionais. Instituto Nacional de Tecnologia, 2003. (Nota Técnica 14).

DAVENPORT, Thomas H.; PRUSAK, Laurence. Ecologia da informação: porque só a tecnologia não basta para o sucesso na era da informação. São Paulo: Futura, 1998.

DRAGO, Isabela; SILVA, Helena Fátima Nunes; SATO, Aparecida Scroch. Contribuições do movimento nós podemos Paraná para a criação e compartilhamento de conhecimentos. Em Questão, Porto Alegre, v. 20, n. 1, p. 165-188, jan./jun. , 2014.

FEDERAÇÃO DAS INDÚSTRIAS DO ESTADO DO PARANÁ - FIEP. Perfis profissionais do futuro: metal mecânico. Curitiba: SESI/SENAI, 2010.

GARVIN, David A. Construindo a organização que aprende. In: HARVARD BUSINESS REVIEW. Gestão do Conhecimento. Rio de Janeiro: Campus, 2000. P. 50-81

HAAAPALAINEN, Pävi; MÄKIRANTA, Anne. Acquiring and sharing knowledge in SMEs: a casen the manufacturing industry. Journal of Knowledge Management Practice, Thousand Oaks, v. 14, n. 1, mar. 2013.

IPE, Minu. Knowledge sharing in organizations: a conceptual framework. Human Resource Development Review, Thousand Oaks, v. 2, n. 4, p. 337-359, dec. 2003.

$\mathrm{KOCH}$, Anne. Firm-internal knowledge integration and the effects on innovation. Journal of Knowledge Management, Thousand Oaks, v. 15, n. 6, p 984-996, 2011. 
Karoline Aparecida Scroch Sato; Helena de Fátima Nunes Silva; Isabela Drago; Sônia Maria Breda

Criação e compartilhamento de conhecimento: perfis profissionais para o futuro da indústria paranaense

LEONARDI, Juliana; BASTOS, Rogério Cid. Bases epistemológicas da teoria de criação de conhecimento organizacional. Perspectivas em Gestão e Conhecimento, Paraíba, v. 4, n. 2, p. 3-18, jul./dez., 2014.

LIN, Hsiu-Fen. Effects of extrinsic and intrinsic motivation on employee knowledge sharing intentions. Journal of Information Science, Thousand Oaks, v. 33, n. 2, p. 135-149, 2007.

MUSSI, Clarissa Cordeiro; ANGELONI, Maria Terezinha. Compartilhamento do conhecimento no contexto de projetos de tecnologia da informação. In: ANGELONI, Maria Terezinha (Org.). Gestão do Conhecimento no Brasil: casos, experiências e práticas de empresas públicas. Rio de Janeiro: Qualitymark, 2008. p. 61-74.

NONAKA, Ikujiro. A empresa criadora de conhecimento. In: HARVARD BUSINESS REVIEW. Gestão do conhecimento. Rio de Janeiro: Campus, 2000. p. 27-49.

NONAKA, Ikujiro; TAKEUCHI, Hirotaka. Criação de conhecimento na empresa: como empresas japonesas geram a dinâmica da inovação. 5 . ed. Rio de Janeiro: Campus,1997.

OLIVEIRA JUNIOR, Moacir de Miranda. Competências essenciais e conhecimento na empresa. In: FLEURY, Maria Tereza Leme; OLIVEIRA JUNIOR, Moacir de Miranda (Org.). Gestão estratégica do conhecimento: integrando aprendizagem, conhecimento e competências. São Paulo: Atlas, 2001. p. 121-156

OLIVEIRA, Rozilda Rodrigues; ALVES FILHO, Bartolomeu de

Figueiredo. Contexto de compartilhamento do conhecimento: o caso do Serpro-Recife. In: ANGELONI, Maria Terezinha. Gestão do conhecimento no Brasil: casos, experiências e práticas de empresas públicas. Rio de Janeiro: Qualitymark, 2008. p. 51-60

ONO, Arnaldo Turuo. Uma proposta de inter-relação entre a teoria da criação do conhecimento e a espiral da aprendizagem. Pretexto, Belo Horizonte, v. 15, n. 2, p. 58-76, 2014.

OUTI, Nilton Sadao; STRAUHS, Faimara Rocio. Visão nacional do processo de criação do conhecimento japonês: estudo de caso AirCon do Brasil. In: KM BRASIL CONGRESSO BRASILEIRO, 2004, São Paulo. Anais... São Paulo: KM Brasil, 2004. v. 1.

SANTOS, Antonio Raimundo et al. Gestão do conhecimento: uma experiência para o sucesso profissional. Curitiba: Champagnat, 2001.

SENAI. Setores portadores de futuro para o estado do Paraná horizonte de 2015: relatório técnico. Curitiba: SENAI, 2005. 
Karoline Aparecida Scroch Sato; Helena de Fátima Nunes Silva; Isabela Drago; Sônia Maria Breda

Criação e compartilhamento de conhecimento: perfis profissionais para o futuro da indústria paranaense

SENGE, Peter M. A quinta disciplina. São Paulo: Best Seller, 2003.

STEWART, Thomas A. Capital intelectual. Rio de Janeiro: Campus, 2002.

SVEIBY, Karl Erick. A nova riqueza das organizações: gerenciando e avaliando patrimônios de conhecimento. Rio de Janeiro: Campus,1998.

TERRA, José Cláudio Cyrineu. Gestão do conhecimento: o grande desafio empresarial. São Paulo: Negócio, 2001.

THENMOZHI, M. Evolution of management theory. 2010. Disponível em: <http://www.nptel.iitm.ac.in/courses/IIT-

MADRAS/Management_Science_I/ Pdfs/1_2.pdf>. Acesso em: 23 jul. 2015.

TONET, Helena Correa; DA PAZ, Maria das Graças Torres. Um modelo para o compartilhamento de conhecimento no trabalho. Revista de Administração Contemporânea, Curitiba, v. 10, n. 2, p. 75-94, abr./jun. 2006.

VON KROGH, Georg Von; ICHIJO, Kazuo; NONAKA, Ikujiro.

Facilitando a criação de conhecimento: reinventando a empresa com o poder da inovação contínua. Rio de Janeiro: Campus, 2001.

ZHENG, Suli et.al. Knowledge-based dynamic capabilities and innovation in networked environments. Journal of Knowledge Management, Thousand Oaks, v. 15, n. 6, p. 1035-1051, 2011.

Title

Creation and sharing of knowledge in the project professionals profiles for the future of state of Paraná's Industries

\section{Abstract}

Introduction: A study on the creation and sharing of knowledge in the project Professional Profiles for the Future of State of Paraná's Industries, of the Federation of Industries of the State of Paraná (FIEP)'s Observatories of Prospecting.

Objective: analyze the process from the case of Paraná, based on the assumptions: organizations active in prospecting activities are intense in the creation and sharing of knowledge; making the individual knowledge collective is one of the main challenges of innovative organizations. 
Karoline Aparecida Scroch Sato; Helena de Fátima Nunes Silva; Isabela Drago; Sônia Maria Breda

Criação e compartilhamento de conhecimento: perfis profissionais para o futuro da indústria paranaense

Methodology an exploratory and descriptive study that draws on literature, documentation and observation based on the participation in nine experts' workshops linked to the project (sample by typicality geared to sectors of mechanical metal, plastic, IT and environment) and interviews with the rapporteurs of the workshops. Compare empirical material with the relevant referential in order to highlight aspects of this management practice.

Results: based on the results of the analysis of the organization's documentation, the observations during the panels and interviews, it was noticed that the project Professional Profiles for the Future of State of Paraná's Industries includes all the five phases of knowledge creation and the enablers of knowledge.

Conclusions: The results of interviews confirm the results obtained during the observations, which allows to realize that there was consensus in the discourse of the management team and the workshop's experts in relation to what is expected as a professional profile for the future of the industry of Paraná.

Key-words: Knowledge Creation. Knowledge Sharing. Knowledge Management.

\section{Titulo}

Creacion y compartimiento de conocimiento: perfiles profesionales para el futuro de la industria paranaense

\section{Resumen}

Introducción: Estudio sobre creación y compartimiento de conocimiento en el proyecto Perfiles Profesionales para el Futuro de la Industria Parananense, de los Observatorios de Prospección del Sistema Federación de las Industrias del Estado de Paraná (FIEP).

Objetivo: analiza el proceso a partir del caso paranaense, partiendo de los presupuestos: las organizaciones actuantes en actividades de prospección son intensas en la creación y compartimiento del conocimiento; tornar colectivo el conocimiento individual constituye uno de los principales desafíos de las organizaciones innovadoras.

Metodología: investigación exploratoria y descriptiva, se vale de investigación bibliográfica y documental, observación fundamentada en la participación en los paineles de nueve especialistas conectados al Proyecto (muestra por tipicidad envuelta a los sectores metal mecánica, plástico, TIC's y medio ambiente) y realización de entrevistas con los relatores de los paineles. Coteja el material empírico levantado con el referencial pertinente de modo a evidenciar aspectos de esa práctica de gestión.

Resultados: con base en los resultados obtenidos de los análisis de la documentación de la organización, de las observaciones durante los paineles y de las entrevistas, se percibió que el proyecto Perfil Profesionales para el futuro de la Industria Paranaense contempla las cinco fases del proceso de creación del conocimiento y también los capacitadores del conocimiento. 
Karoline Aparecida Scroch Sato; Helena de Fátima Nunes Silva; Isabela Drago; Sônia Maria Breda

Criação e compartilhamento de conhecimento: perfis profissionais para o futuro da indústria paranaense

Conclusiones: Los resultados de las entrevistas confirman los resultados obtenidos durante las observaciones, lo que permite percibir que hubo consenso en el discurso del equipo gestor y de los panelistas en relación al que se espera como perfil profesional para el futuro de la industria paranaense.

Palabra-clave: Creación del conocimiento. Compartimiento del conocimiento. Gestión del conocimiento.

Recebido em: 18/09/2014

Aceito em: 01/11/2015 